\title{
Student Teachers and Mental Health: A Qualitative Study on Students' Experiences Living With a Mental Health Condition
}

\author{
Diane Kratt, EdD \\ Florida Gulf Coast University, Fort Myers, Florida, United States \\ (iD) https://orcid.org/0000-0002-8353-9807 \\ Michael Houdyshell, PhD \\ Florida Gulf Coast University, Fort Myers, Florida, United States \\ (iD) https://orcid.org/0000-0002-8353-9807
}

Contact: $\underline{\text { mhoudyshell@fgcu.edu or dkratt@fgcu.edu }}$

\section{Abstract}

\begin{abstract}
Reports of college students living with mental health conditions are common, and the understanding of their connection to academic success is increasing. University campuses strive to meet the psychological needs of their students with a variety of institutionalized practices. However, a question can be raised about how much individual faculty members and colleges know about their specific students' mental health needs and whether there are ways to assist those students at that level. This is a case study on a group of 17 student teachers in the College of Education at a university in the Southern United States who self-reported that they were living with symptoms of a mental health condition. Through individual interviews, the researchers asked student teachers to describe their symptoms and explain their perceptions of how they alleviate the symptoms to manage their life as a college student. Results of the study were reported thematically and categorized as (a) an increase in negative thoughts and behaviors, (b) absence of positive traits and abilities, and (c) self-identified coping strategies and external support. Discussion and recommendations regarding the findings are included.
\end{abstract}

Keywords: college mental health; coping strategies; mental health symptoms; mental health literacy

Date Submitted: September 3, 2019 | Date Published: April 8, 2020

\section{Recommended Citation}

Kratt, D., \& Houdyshell, M. (2020). Student teachers and mental health: A qualitative study on students' experiences living with a mental health condition. Journal of Social, Behavioral, and Health Sciences, 14, 53-67. https://doi.org/10.5590/JSBHS.2020.14.1.05

\section{Introduction}

Students make the critically important transition from adolescence to emerging adulthood during the college years (Arnett, 2000). During this transitional period, students experience a variety of challenges including identity development, sexuality, substance abuse, grief, loss, family dysfunction, and changes in values 
Kratt \& Houdyshell, 2020

(Sharma, 2012). In addition, specific stressors faced by students enrolled in college include new living arrangements, homesickness, academic achievement and expectations, time management, and social maladjustments (Linden \& Jurdi-Hage, 2017). These stressors may affect academic performance and lead to feelings of being overwhelmed. Linden and Jurdi-Hage reported that $85 \%$ of college students regularly feel overwhelmed by everything they must do in their lives. For many college students, stress and feelings of being overwhelmed can be associated with or related to mental health conditions, especially during a significant transitional period in their lives (Cuijpers et al., 2016; Pedrelli et al., 2015). Both studies posited that the stress of starting and attending college was one of the top reasons that college students face a mental health problem or condition. The other reasons were academic pressure and arriving on campus with an existing mental health condition (Pedrelli et al., 2015). Alarmingly, Blanco et al. (2008) suggested that 12-50\% of all college students meet the criteria for one or more common mental health disorders.

A study based on survey information from more than 155,000 students across 196 campuses reported that from 2007 to 2017 , treatment for mental health conditions nearly doubled, from $19 \%$ to $34 \%$ (Lipson et al., 2018). In addition, Kessler et al. (2007) reported $75 \%$ of people with a mental health condition have shown symptoms by the age of 25, which includes a significant portion of college age students. Lipson et al.'s (2018) study also found the percentage of students living with a lifetime mental health diagnosis rose from $22 \%$ in 2007 to $36 \%$ in 2017. These high rates of stress and mental health conditions can put students at risk for academic failure and graduating.

Common mental health problems in college students include anxiety, mood disorders, and issues related to substance abuse (Pedrelli et al., 2015). Recent responses from the American College Health Association's (2017) National College Health Assessment indicated 21.6\% of college students reported having anxiety, and $17.9 \%$ reported having depression. The survey also showed a 15\% increase from 2008 to 2017 of students reporting overwhelming anxiety over the last year. In addition, students in some academic majors can be more prone to experiencing mental health conditions. For example, a study found $41 \%$ of student teachers reported dealing with issues of depression and hostility (Uzman \& Telef, 2015). Additionally, in testing the concurrent validity of the Student Teacher Professional Identity Scale, Živković (2018) found student teachers commonly described issues of stress and burnout during their programs. This scale examines how future educators prepare for their teaching career through the development of a professional teaching identity while also attempting to understand early or preservice teachers emerging identities. Research has also shown new teachers (i.e., those with 1-3 years of teaching) have a high prevalence of mental health conditions such as anxiety and depression (Seth, 2016; Walter et al., 2006; Woudstra et al., 2018). In general, the teaching profession is characterized by issues of mental health impairment due to work-related stress (Seibt et al., 2013; Wang et al., 2015).

People experiencing symptoms of a mental health condition may develop coping strategies. Coping strategies can be defined as the means to regulate oneself in the response to stress or other anxiety-related issues (Bettis et al., 2017). Coping strategies also help students enhance their resiliency in the face of adversity during their college years, including in recovering from challenges related to mental health (Eisenberg et al., 2016). Specifically, coping interventions can reduce symptoms of attention-deficit/hyperactivity disorder, generalized anxiety disorder, and depression and have been effective in treating mental health conditions for college students (Bettis et al., 2017).

Coping strategies as part of being resilient also allow college students to recover from academic challenges such as failing an exam (Eisenberg et al., 2016). Yet, some students dealing with a mental health condition still do not apply the necessary coping strategies to be academically and personally successful while enrolled in higher education (Hartrey et al., 2017). In addition, Eagan and colleagues (2013) found that a decrease in resiliency among college students has also led to a decrease in mental health. The use of coping strategies, 
including seeking external support, may reduce symptoms, thus making academic success and retention more likely.

\section{Research Questions}

Of specific interest in the current study were the two following research questions:

Research Question 1: What symptoms, related to mental health, are student teachers experiencing?

Research Question 2: What, if anything, has helped relieve or lessen those symptoms?

\section{Method}

In the spring of 2018, two researchers from a College of Education at a 4-year university in the Southeastern United States conducted a qualitative case study to examine the lived experiences of student teachers who have self-reported challenges with their own mental health. The College of Education offers seven undergraduate degrees, six of which lead to state teacher certification. At the time of this study, the College of Education had approximately 700 undergraduate students enrolled in a degree program. Each student enrolled in one of the six teacher education majors leading to state certification must complete two student teacher internships in their final two semesters.

An instrumental case-study approach was used to gather information (Creswell, 2013; Stake, 2005; Yazan, 2015; Yin, 2014) in an attempt to shed light on the issue of mental health in teacher preparation and how student teachers live with a mental health condition. This type of study was supported in the literature to develop a framework in understanding the lived experiences of student teachers who have a mental health condition and how the College of Education could support their success (Merriam, 2009; Stake, 1995, 2005).

The first part of the study was an anonymous online survey with 10 closed-response questions, which was sent to all student teachers in their last or next-to-last semester at the university. This group of students was solicited to ensure that all participants would be in their final two semesters at the university, and in one of two required student teaching internships. The survey link was emailed during January and February 2018 and was accessible for 2 weeks. Questions on the survey were demographic in nature, including grade point average, major, extracurricular activities, and experience with a mental health condition. A second part of the study included face-to-face interviews with participating student teachers and the two researchers. During the online survey, students who reported having a mental health condition were invited to participate separately in a face-to-face interview with both researchers at a later date. The interviews were conducted from February to April 2018. The third part of this study involved reviewing their student teaching course evaluations. The researchers were faculty members who had access to all evaluations, which were completed by student teachers' university supervisor or cooperating teacher. The entire set of data from all phases produced group (survey) and individual (interview and evaluation) themes, which were analyzed for relevancy and are presented in this study. Approval was given by the university's institutional review board (Number 2017-41) for all phases of this study.

\section{Data Collection}

The researchers employed the method of data collection known as triangulation. This means that several data types were collected for analysis. Using triangulation as a data collection method allowed the researchers to create validity in the study with the use of multiple data sources (Hussein, 2009). The study's data included the survey, interviews, and student teacher evaluations. 


\section{Online Survey}

An electronic link was emailed to all student teachers for an online survey. Out of 117 eligible students, $59(n=$ 53 female, $n=6$ male) completed the anonymous online survey. An online consent form was required for every student who responded to the survey. The survey was used to collect some demographic information, learn more about this group of students, and ultimately recruit participants for the in-person interviews. Table 1 provides demographic information for the online survey participants.

Table 1. Participant Demographics

\begin{tabular}{lcc}
\hline \multicolumn{1}{c}{ Demographic } & $\boldsymbol{n}$ & \% \\
\hline Gender & 53 & 89.8 \\
Female & 6 & 10.2 \\
Male & & \\
Age group, years & 45 & 76.3 \\
$\quad \leq 22$ & 14 & 23.7 \\
$\geq 23$ & & \\
Race/ethnicity & 46 & 77.9 \\
Non-Hispanic/White & 9 & 15.3 \\
Hispanic & 3 & 5.1 \\
African American & 1 & 1.7 \\
Mixed & & \\
Academic major & 7 & 11.9 \\
Early childhood & 32 & 54.2 \\
Elementary education & 10 & 16.9 \\
Special education & 3 & 5.1 \\
Secondary biology & 3 & 5.1 \\
Secondary social science & 4 & 6.8 \\
Secondary math & & \\
Mental health condition & 27 & 45.8 \\
Yes & 32 & 54.2 \\
No & & \\
\hline
\end{tabular}

Survey respondents were also asked their major grade point average, number of hours working off campus per week, and extracurricular activities they were currently involved in on or off campus. The critical question on the survey asked if they were currently living with a mental health challenge or condition, and 27 out of the 59 students indicated that they were. Those participants were asked to provide an email address if they were willing to receive follow-up contact by the researchers for participation in a face-to-face interview as part of this study.

\section{Face-to-Face Interviews}

The researchers used the online survey responses to solicit participants for the face-to-face interviews. This type of convenient, purposeful sampling was conducted to add credibility to the study and reduce any participant bias (Patton, 2002). During this stage, the researchers interviewed 17 student teachers individually; 15 participants were female, and two were male. The interviews were semistructured due to the use of a 10-question protocol with predetermined questions that were asked of every participant (see the Appendix). Because of the open-ended nature of the interview, participants were able to tell their story in their own way and helped to add richness or clarification to their responses. Participants were asked about 
their lived experiences with a mental health condition, which was not defined for them. Each student teacher was able to share their own story as they perceived it. Diagnoses, symptoms, and treatments were all selfreported by each participant. Each interview lasted approximately 30-60 min. A separate consent form was signed by each participant at the beginning of the interview. All interviews were transcribed by a paid transcriptionist; a copy of each transcription was then sent to individual participants. Each participant was invited to read through their transcription to check that their words, thoughts, and meanings were accurately depicted in the interview. Creswell (2013) suggested this method increases credibility by allowing participants to review findings for accuracy.

\section{Performance Evaluations}

In this study, the role of both researchers was that of College of Education faculty with the primary responsibility of working with the student teacher internship program for all students enrolled in any of the six teacher-preparation programs. As faculty, the researchers were able to review evaluations being completed by the student teachers' university supervisor and cooperating teacher. One of the instruments uses Charolette Danielson's (2013) framework for teacher evaluation to assess four domains; planning and preparation, classroom environment, instruction, and professional responsibilities. Another instrument uses Interstate Teacher Assessment and Support Consortium (Council of Chief State School Officers, 2013) standards from four categories; the learner and learning, content knowledge, instructional practice, and professional responsibility. The student teacher evaluations are used to gauge performance and disposition success measured by the program.

\section{Data Analysis}

All data were analyzed by both researchers using a reiterative process. Zhang and Wildemuth (2017) described the reiterative process as allowing the researcher to refine ideas, not to increase the original sample size. First, the survey results were carefully read and coded. Then, each interview was transcribed by an outside professional transcriptionist and coded for relevant themes by each researcher independently. Finally, student evaluations were reviewed for performance and disposition evidence relating to survey and interview responses.

The areas reviewed were "professional responsibilities" on the performance instrument and "meets requirements" on the disposition instrument. After an exhaustive, reiterative process of coding for themes, the researchers met to discuss their individual themes and ideas.

To add validity, the researchers asked doctoral students in a qualitative research methods course to review the transcriptions (with redacted personal identifiers) for themes. Their ideas were then compared to those of the researchers. The findings were drawn primarily from the themes developed after conducting, transcribing, and reviewing all the individual interviews. The survey and evaluation data merely supported what the student teachers shared during the interviews. Pseudonyms are used for all interview participants from the study to protect their identities. Any personal opinions and other findings outside of the coded information are presented in the discussion section.

\section{Findings}

Three themes related to student teachers living with a perceived mental health condition emerged during the reiterative data-review process: (a) negative thoughts and behaviors, (b) absence of positive traits and abilities, and (c) self-imposed coping strategies and external support. Each of these three themes will be discussed in the following sections. 
Kratt \& Houdyshell, 2020

\section{Theme 1: Increase in Negative Thoughts and Behaviors}

Mental health conditions can influence a person's way of thinking, feeling, and behaving. Sometimes, negative thoughts and behaviors that may not ordinarily be present can occur when a person is experiencing a mental health condition. In this study, participants described examples of negatively perceived thoughts and behaviors as a sign or symptom of their mental health condition, but a few of the signs and symptoms were common for many participants. The most common negative feelings were fear and hopelessness, and the most common negative behavior was isolation. Living in fear with little hope of things getting better and isolating oneself create barriers in life, including for students. The student teachers described what it has been like for them.

\section{Fear}

Fear was described in different ways such as panic attacks, fear of failure, worry, stomach problems, and the need to be in control. For instance, Susan described herself as having "severe anxiety when it came to everything. I was scared of life." Kathy described how she worried about being on time, having correct school work, and missing something important. She said that she was not trying to be perfect for herself, but instead, she was always trying to please other people. "I want to make sure it's good enough for them." A third example came from Toni, who stated, "I would pace and have major panic attacks with not knowing what to do with myself. I was constantly overthinking and letting my fearful thoughts control me.” Many participants, like Toni, described their need to be in control of everything, always. Being in control temporarily took away some of the feelings of fear for them.

Given that high-stakes teacher certification exams are a graduation requirement in this teacher-preparation program, it was not surprising to learn that many of the participants experienced test anxiety. For example, six different participants spoke about how test anxiety has been a barrier for them as a College of Education student. Unfortunately, once they did poorly on an exam, it only made their fears worse for the retake. In some cases, it took multiple attempts to receive a passing score for each of the three required certification exams, costing additional time and money. Megan described,

Anytime I have to take those tests, I get so stressed out and cry. I am one of those people who are not a good test taker, so I have to drop so much money to take these tests because I always have to take them several times before I pass.

\section{Hopelessness}

Participants often sounded hopeless in their descriptions of themselves during an episode or a rough time. Susan stated, "I just didn't want to do anything." Heidi said she "wasn't happy at all." A third participant, June, specified that she did not feel her work in school was worth anything, which made her feel, "I'm never going to be making an impact.” These students described feelings of unhappiness and lacking purpose, attributed to their own struggle with a mental health condition.

Feeling hopeless can also include suicidal ideation, which occurred for many of the participants. Some of them described a time when they considered suicide but had not acted upon it and did not feel it was a current problem. For example, Janet stated that prior to treatment, she was "pretty regularly having suicidal thoughts." June said she was registered at her high school for being on a suicide watch and came close to being involuntarily institutionalized on a few occasions. However, things had gotten much better for her since then. Heidi, however, shared that keeping herself alive was a constant battle, even at that moment. "I've always had, ever since I was little, I had thoughts about suicide," she stated.

Heidi was an excellent student who seemed to have many friends and appeared happy to those around her. However, her inner thoughts were vastly different from what she showed on the outside. Heidi stated that it was important to her that these thoughts be kept secret from others and that she had gotten good at hiding 
them. She said that even her mother did not know for the longest time because she presented as being fine, but "on the inside, I was battling like every day, I mean every day." Suicidal ideation is the most extreme form of hopelessness, yet it was a typical part of life for many of the participants in this study.

\section{Isolation}

Isolation was another commonly described symptom. Participants stated that they did not want to leave the house and that they preferred being alone. One example came from Kathy, who said it was common for her to make plans with friends ahead of time but then cancel when the day came. She said, "I just don't want to leave my house, get out of bed, or see anybody." Additionally, Amanda stated, "I definitely didn't hang out as much with people" during a time when she was overwhelmed as a college student. Besides their social life, isolation also impacted their educational life. Several participants commented on class absences. For example, Susan stated, "There were times when it was a bad morning, and something drew an anxiety attack. I don't know what it was, but I had to miss class." The participants missed class for various reasons. Sometimes it was because of physical symptoms like stomachaches and chest pain, and other times, for lack of motivation or fear of failure. Feelings of wanting to be alone and isolating themselves affected their learning and grades, along with their social life.

\section{Theme 2: Absence of Positive Traits and Abilities}

While experiencing negative thoughts and behaviors, it is also possible for some positive traits and abilities to be taken away from a person due to their mental health condition. This can mean double the problems for people living with a mental health condition and increases the difficulty level of basic life functions. In their own descriptions of what having a mental health condition has been like for them, the participants described the absence of some common positive traits and abilities. Three examples of lacking common helpful abilities emerged and intertwined: the ability to cope with minor problems, the ability to focus and concentrate, and emotional resiliency. For example, some participants described times when something trivial would happen, but they would find themselves dwelling on it to the point of being unable to concentrate on anything else and would often end up crying uncontrollably.

\section{Inability to Cope With Minor Problems}

Although school work was expected as a student, it often became a minor problem for the participants in this study, and the most common way to deal with the feelings of being overwhelmed was for them to ignore or procrastinate on the work they knew was ahead. Susan said she would simply put off assignments. Toni stated, "It was hard to complete any type of class during that time." Furthermore, Amanda added that "It was easy for me to just forget about my assignments even though getting back to them was very stressful."

June has since worked with a therapist to make better use of her planner and avoid these types of problems. Prior to this strategy however, she said she had the habit of procrastinating. She remembered a time when she was thinking,

There's no way that I'm going to be able to complete all this work and I was thinking that my parents shouldn't pay so much for me to be here because I can't do it. I just wanted to give up.

An inability to cope with typical problems can lead to feeling defeated and a desire to give up.

\section{Inability to Focus and Concentrate}

As a college student, the ability to focus and concentrate is important. In dealing with their mental health condition, the participants described the difficulty in being able to do so, especially due to their mental health condition. For example, Darrell stated, "My anxiety often made it harder to focus on certain things, like specific tasks." Furthermore, Kathy said, "I dwell on every little thing, which makes it hard to complete assignments and just adds to the stress." Toni had similar experiences and described the inability to focus and 
Kratt \& Houdyshell, 2020

concentrate as times when she was completely obsessed over one thought, which distracted her from what she was supposed to be doing. At times, their inability to focus and concentrate impacted their success as a college student.

\section{Low Emotional Resiliency}

Some of the participants gave examples indicating their struggles with a mental health condition. Crying was a frequently reported response as an example of low emotional resiliency used by most of the participants: "I cried every day" (Susan); "I had one of those crying episodes during student teaching" (Janet); "I was constantly upset all the time, crying" (Heidi); "It really stopped me from being able to function because I was just like crying all the time" (Sara). As June described her sadness, she began to cry: "I have been working really hard to go against it (sadness) and oh my gosh, I did not think I was going to cry. Can I have a Kleenex?" Many of the participants' stories were emotional, and it was easy to see how their low emotional resiliency sometimes affected their ability to persevere.

\section{Theme 3: Coping Strategies and External Support}

As part of the interview, participants were asked what they did to help themselves cope, especially during challenging episodes. They were also asked what external support they had sought out to assist them living with a mental health condition. Responses varied, but all the coping strategies and additional support had a positive effect in the lives of the student teacher participants. Elizabeth summed up the whole theme: "For me, eating, exercise, and surrounding myself with positive people definitely help."

\section{Coping Strategies}

Everyone agreed that coping, or self-care, strategies were important for their everyday success. However, not all the participants used the same strategies. The most popular examples included exercise, music, and reading. Kathy stated, "Reading is a huge help to me. I love to read." Amanda said, "Running and listening to music have helped me with my stress." Other strategies were also mentioned in the interviews, but the responses were unique to that one participant. Heidi discovered that keeping herself busy was especially helpful. She said, "I like keeping my mind off things, so I stay as busy as I can. When I am on my own, that's when I think a lot. When I am teaching, working, or playing sports, I am not thinking." Other examples of coping strategies included removing gluten from their diet, starting a nonprofit organization, and using breathing exercises. No participants disclosed anything related to self-medicating with drugs or alcohol; instead, everything mentioned was positive and helpful in their lives.

\section{External Supports}

Many participants sought external support and help from others. It was typical to have participants mention their friends as support systems. For example, Elizabeth stated that having a few close friends and forming relationships with them helped her get through tough times. In addition, some of the participants were clients at the university's Counseling and Psychological Services (CAPS) office. From CAPS, they received therapy, attended support groups, and were prescribed medication. Janet was one of those who said, "I go to CAPS right now. I went to the psychiatrist there and have talked about anxiety and depression." Several students confided that they have either tried a prescribed medication or are currently taking one. Their stories of being on medication were filled with both positive and negative results, but most felt that, overall, medication was a positive form of support. Other external support included being enrolled in the university's Adaptive Services for classroom accommodations, the use of self-help apps on their mobile device, and staying connected to family; one participant had a service dog for anxiety. When asked about receiving support from others, Fran stated, "I am close with my mother and I call her every day." Even though the participants weren't always knowledgeable about the field of mental health, most knew that they needed some additional support and sought it out as a college student. 
Kratt \& Houdyshell, 2020

\section{Discussion}

\section{Symptoms}

The symptoms experienced by the student teacher participants were consistent with common symptoms associated with mental health conditions such as anxiety and mood disorders such as depression. For example, the participants described anxious feelings and being overwhelmed. In those times, they often cried, withdrew, failed to perform, and felt a variety of physical symptoms. In addition, some participants expressed great feelings of sadness at times and even struggled with suicidal ideation. Research has shown that students can face crippling bouts of stress and anxiety that impact their academic goals (Bieter et al., 2014). Many of the symptoms described by the student teachers are easily misunderstood. One such example came from Heidi, who was once guilty of plagiarizing a part of her homework assignment from a website. The faculty member assumed that she just was lazy or had mismanaged her time when in fact, Heidi was severely struggling psychologically with hopelessness and suicidal thoughts, making it near impossible to focus and complete school assignments. Faculty can identify students sooner and connect them with an appropriate resource or professional for assistance when they have an understanding of basic signs and symptoms of mental health conditions and know how to approach them.

\section{Coping Strategies and Support}

Both intentionally and unintentionally, the student teacher participants engaged in effective coping strategies, treatment, and support to alleviate their symptoms. Bettis et al. (2017) described coping strategies as "conscious purposeful efforts to regulate emotion, cognition, behavior, physiology, and the environment in response to stress" (p. 313). Although self-medicating can be thought of as a coping strategy, no participants shared anything related to the use of drugs or alcohol. As a matter of fact, no negative behaviors were shared in connection to relieving their symptoms. It was unclear if this was because they were not engaging in that behavior or if they just did not want to disclose it during interviews. However, the variety of coping strategies described did help the student teachers. For example, listening to music and engaging in exercise are known to help people manage mental health symptoms related to anxiety and mood disorders. Misra and McKean's (2000) research showed some correlation between reducing academic stress and anxiety and engaging in leisure or recreational activities for college students. They were also the two most common strategies named by participants. Moreover, not all participants intentionally engaged in coping strategies. Some had not thought of their behavior in that way until the interview, but then realized the reason during the discussion. In other instances, participants had been taught strategies or they had researched ideas for themselves. For example, Sara, who took a university course on mindfulness, said she learned a great deal and felt it was her favorite course and the most useful one in her whole college career. Learning about self-care and coping strategies might help college students manage their stress and mental health symptoms more effectively.

Support systems were another important aspect in the lives of the participants. Students used the support of their friends, family, and college professors to manage daily problems and activities. Furthermore, the use of therapists and medications also supported many of the student teacher participants. Students who used systems of support felt capable of managing their life and were hopeful for the future.

\section{Implications and Recommendations}

\section{Mental Health Conditions as Barriers}

The student teacher participants shared examples of times when mental health symptoms created barriers to their academic or personal success. Disabling panic attacks is an example of this when students were not able to concentrate or even attend class. Another example is the inability to learn new information during times of obsessive and racing thoughts. Because research has shown that academic pressures can lead to stress and a 
lack of academic success (Kumaraswamy, 2013; Misra \& McKean, 2000), creating a safe and positive learning environment may help students reduce or eliminate barriers to learning.

The participants often mentioned examples of helpful faculty behavior and class management. One example was when course instructors were approachable and flexible so that participants felt comfortable sharing their reality with them. Another example was that they liked assignment directions to be clear, concise, easily accessible, and consistent. Arguably, these factors enhance students' ability to manage their time, which Misra and McKean (2000) showed lowers academic stress and anxiety in college students. A third example was that familiarity and predictability made things easier. Colleges that are intentional about their learning environment may indirectly improve student learning and retention.

\section{Training for Faculty and Students}

Basic mental health literacy can improve knowledge, awareness, and sensitivity. Mental health literacy is defined as understanding how to obtain and maintain good mental health, understanding mental disorders and their treatments, developing capacities to decreasing stigma, and developing capacities to enhance helpseeking efficacy (Carr et al., 2017; Kutcher et al., 2015; Kutcher et al., 2016). Learning more about mental health was overwhelmingly the most shared recommendation from the participants regarding how to improve the college's practice. They felt that including mental health training for faculty, as well as for students, could benefit everyone. One reputable training course that is easily available is Mental Health First Aid (see mentalhealthfirstaid.org). By offering this course, faculty and students can learn how to approach people who may be experiencing a mental health condition or crisis and assist them in receiving the appropriate professional help. This one course begins to break down some of the walls associated with stigma and ignorance toward mental health. Each participant in the course also receives a resource manual full of information and Internet resources to explore on their own. Research on Canadian teaching education programs seems to support this idea. Carr et al. (2017) noted the continued need for mental health literacy for teachers to increase awareness of mental health conditions. Besides this initial course, other training can be provided to continue the professional development in related areas. Increasing the literacy of everyone regarding mental health is a good place to start.

\section{Implement Self-Care Strategies}

Personal well-being and self-care are essential in managing today's stressful lives, not to mention for those living with a mental health condition. In addition, self-care helps build resiliency in college students, which allows them to cope with academic stress exacerbated by a mental health condition (DeRosier et al., 2013). The study's participants all mentioned things they did to manage their symptoms and feel better overall. Some learned about coping strategies from professors, therapists, friends, and online. Being more intentional about emphasizing self-care and teaching coping strategies is a recommended intervention. Increasing the awareness of self-care strategies with faculty and students may assist in managing stress and mental health symptoms.

\section{Provide Support}

Although university campuses have prevention centers and psychological services, colleges may be able to offer additional support to their individual students. Additional support outside of the traditional on-campus mental health services is even more important, as the Association for University and College Counseling Center Directors reported that during 2016-2017, 34\% of centers had to put some students on a waitlist to receive mental health services (Burwell, 2018). The student teacher participants shared how friends and college faculty were often a means of effective support. However, they also made several suggestions for how the college could improve in providing support. The most popular suggestion was to have peer support groups so that they could talk to and learn from students like themselves. A study on mental health stigma and social support from peers among college students suggests some positive benefit from enhanced social support for students who self-identify as having a mental health condition or are at risk of developing one (Denenny et al., 
2015). They also suggested that the college should have a person available, other than academic advisors, as a resource for a variety of problems. They said it would really help to have an understanding person who was very familiar with the college to help navigate their transition through the college and adulthood. Some participants even suggested that this person could help organize the peer support groups they requested. In addition, they could provide yoga classes, mindfulness training, and other self-help type trainings throughout the academic year. They understood that the university probably already offered the things they suggested, but each of them spoke about the importance of being in a familiar setting with people you know, who have the same professional goals. They all wanted the support directly from their college, not the university. Finding ways for a college to better support its students emotionally is a recommendation from this study.

\section{Study Limitations}

\section{Size}

Because this was a small, localized study focused entirely on one teacher education program in a college of education, the size of the study may be a limitation in generalizing these results to other teacher education programs. Although the need for increased mental health awareness, education, and resources is documented in the literature (Atkin \& Rodger, 2016), it is not clear how other teacher education programs work with their students who have mental health conditions. The limited amount of research on this topic would suggest there is a significant lack of understanding of how mental health conditions impact student teacher success, and the need for assistance is great.

\section{Self-Identification}

A second limitation is in how participants reported their mental health condition for the study. The researchers did not limit how students believed they were impacted by a mental health condition, by actual diagnosis or otherwise. Students who participated in the study self-identified as a person with a mental health condition, and no medical information was requested. Understanding the complex nature of mental health conditions, participants may or may not be familiar with how specific mental health conditions emerge versus factors that may influence characteristics of a mental health condition. Students are entering higher education with a much better understanding of how their own mental health is impacted by issues in and out of their control. This in turn creates an environment, diagnosed or perceived, where living with a mental health condition has real implications in the success of students training to be teachers. For teacher education programs across higher education, the need to support and equip their student teachers to become and remain successful teachers is critical. Barriers to student success such as living with a mental health condition create conditions that challenge the success of student teachers in and out of the classroom. Better awareness, education, resources, and research within colleges of education and the profession of teaching about the impact of mental health on student teacher success warrant honest conversations and accountable actions to create environments where living with a mental health condition is manageable and understandable in training future teachers.

\section{Conclusion}

Student voice is important, and in this study, student teachers shared their lived experiences with a mental health condition. Through data collection and analysis, we learned that a significant number of College of Education seniors were experiencing perceived mental health symptoms. The symptoms they described are similarly described throughout research for conditions such as anxiety and mood disorders. They openly shared how those symptoms were often barriers to learning and what things have made school more manageable for them. In addition, the participants described coping strategies such as listening to music, engaging in exercise, using self-help apps, and reading for alleviating their symptoms. At the same time, we learned that intentionally teaching coping strategies to college students was an effective practice. Furthermore, the participants confirmed the belief that support systems are critically important, especially 
peer support. Given the data and discussion, the most important conclusion to draw from this study is that training in mental health literacy and self-care strategies needs to be expanded to include a larger group of people who encounter college students every day, not only mental health professionals. That means faculty, staff, and peers in relation to this study's environmental setting. Additionally, the researchers offer three insights from the study that may affect how teacher preparation programs can use these findings to benefit students training to become teachers. First, if students have better individual mental health, they perform better as students and student teachers in the classroom. Second, as student teachers learn more about mental health, they are also able to approach and refer students in their own classrooms who might be experiencing a mental health condition. Finally, teacher education programs can do more to train faculty and staff and provide support on mental health, which in turn helps with student success and retention.

\section{References}

American College Health Association. (2017). National College Health Assessment undergraduate student reference group. https://www.acha.org/documents/ncha/NCHA-II FALL 2017.pdf

Arnett, J. J. (2000). Emerging adulthood: A theory of development from the late teens through the twenties. American Psychologist, 55, 469-480. https://doi.org/10.1037/0003-66X.55.5.469

Atkin, M., \& Rodger, S. (2016). Pre-service teacher education for mental health and inclusion in schools. Exceptionality Education International, 26(2), 93-118.

Bettis, A. H., Coiro, M. J., England, J., Murphy, L. K., Zelkowitz, R. L., Dejardins, L., Eskridge, R., Adery, L. H., Yarboi, J., Pardo, D., \& Compas, B. E. (2017). Comparison of two approaches to prevention of mental health problems in college students: Enhancing coping and executive function skills. Journal of American College Health, 65(5), 313-322.

Bieter, R., Nash, R., McCrady, M., Rhoades, D., Linscomb, M., Clarahan, M., \& Sammut, M. (2014). The prevalence and correlates of depression, anxiety, and stress in a sample of college students. Journal of Affective Disorders, 173, 90-96. https://doi.org/10.1016/j.jad.2014.10.054

Blanco, C., Okuda, M., Wright, C., Hasin, D. S., Grant, B. F., Liu, S.-M., \& Olfson, M. (2008). Mental health of college students and their non-college-attending peers: Results from the national epidemiologic study on alcohol and related conditions Archives of General Psychiatry, 65(12), 1429-1437.

http://doi.org/10.1001/archpsyc.65.12.1429

Burwell, S. M. (2018). Generation stress: The mental health crisis on campus. Foreign Affairs, 97(6), 150-157.

Carr, W., Wei, Y., Kutcher, S., \& Heffernan, A. (2017). Preparing for the classroom: Mental health knowledge improvement, stigma reduction and enhanced help-seeking efficacy in Canadian preservice teachers. Canadian Journal of School Psychology, 1, 1-13.

Council of Chief State School Officers. (2013). Interstate teacher assessment and support consortium InTASC model core teaching standards and learning progressions for teachers 1.0: A resource for ongoing teacher development.

Creswell, J. W. (2013). A case study. In J. W. Creswell (Ed.), Quality inquiry and research design: Choosing among five approaches (3rd ed., pp. 97-102). Sage.). Sage.

Cuijpers, P., Cristea, I. A., Ebert, D. D., Koot, H. M., Auerbach, R. P., Bruffaerts, R., \& Kessler, R. C. (2016). Psychological treatment of depression in college students: A meta-analysis. Depression \& Anxiety, 33(5), 400-414. https://doi.org/10.1002/da.22461

Danielson, C. (2013). The framework for teaching evaluation instrucment, 2013 instructionally focused edition. https://usny.nysed.gov/rttt/teachers-leaders/practicerubrics/Docs/danielson-teacherrubric-2013-instructionally-focused.pdf 
Denenny, D., Thompson, E., Pitts, S. C., Dixon, L. B., \& Schiffman, J. (2015). Subthreshold psychotic symptom distress, self-stigma, and peer social support among college students with mental health concerns. Psychiatric Rehabilitation Journal, 38(2), 164-170. https://doi:10.1037/prjo000124

DeRosier, M. E., Frank, E., Schwartz, V., \& Leary, K. A. (2013). The potential role of resilience education for preventing mental health problems for college students. Psychiatric Annals, 43(12), 538-544. https://doi.org/10.3928/00485713-20131206-05

Eagan, K., Lozano, J. B., Hurtado, S., \& Case, M. H. (2013). The American freshman: National norms fall 2013. Higher Education Research Institute, University of California, Los Angeles.

Eisenberg, D., Lipson, S. K., \& Posselt, J. (2016). Promoting resilience, retention, and mental health. In H. Levine \& S. R. Stock (Eds.), New directions for student success (pp. 87-95). Wiley.

Hartrey, L., Denieffe, S., \& Wells, J. S. G. (2017). A systematic review of barriers and supports to the participation of students with mental health difficulties in higher education. Mental Health and Prevention, 6(1), 26-43.

Hussein, A. (2009). The use of triangulation in social sciences research: Can qualitative and quantitative methods be combined? Journal of Comparative Social Work, 1, 1-12.

Kessler, R. C., Amminger, G. P., Aguilar-Gaxiola, S., Alonso, J., Lee, S., \& Ustun, T. B. (2007). Age of onset of mental disorders: A review of recent literature. Current Opinion in Psychiatry, 20(4), 359-364. https://doi.org/10.1097/YCO.0b013e32816ebc8c

Kumaraswamy, N. (2013). Academic stress, anxiety and depression among college students-A brief overview. International Review of Social Sciences and Humanities, 5(1), 135-143.

Kutcher, S., Bagnell, A., \& Wei, Y. (2015). Mental health literacy in secondary schools: A Canadian approach. Child and Adolescent Psychiatric Clinics of North America, 24, 233-244.

Kutcher, S., Yifeng, W., Gilberds, H., Ubuguyu, O., Njau, T., Brown, A., \& Perkins, K. (2016). A school mental health literacy curriculum resource training approach: Effects on Tanzanian teachers' mental health knowledge, stigma and help-seeking efficacy. International Journal of Mental Health Systems, 10, 1-9. https://doi.org/10.1186/s13033-016-0082-6

Linden, B., \& Jurdi-Hage, R. (2017). Examining the predictors of mental health outcomes among undergraduate postsecondary students in Canada. Journal of Social, Behavioral \& Health Sciences, 11(1), 1-30. https://doi.org/10.5590/JSBHS.2017.11.1.01

Lipson, S. K., Lattie, E. G., \& Eisenberg, D. (2019). Increased rates of mental health service utilization by U.S. college students: 10-year population level trends (2007-2017). Psychiatric Services, 7o(1), 60-63. https://doi.org/10.1176/appi.ps.201800332

Merriam, S. B. (2009). Qualitative research: A guide to design and implementation. Wiley.

Misra, R., \& McKean, M. (2000). College students' academic stress and its relation to their anxiety, time management, and leisure satisfaction. American Journal of Health Studies, 16(1), 41-51.

Patton, M. Q. (2002). Qualitative research and evaluation methods (3rd ed.). Sage.

Pedrelli, P., Nyer, M., Yeung, A., Zulauf, C., \& Wilens, T. (2015). College students: Mental health problems and treatment considerations. Academic Psychiatry, 39(5), 503-511. https://doi.org/10.1007/s40596014-0205-9

Seibt, R., Spitzer, S., Druschke, D., Scheuch, K., \& Hinz, A. (2013). Predictors of mental health in female teachers. International Journal of Occupational Medicine \& Environmental Health, 26(6), 856-869. https://doi.org/10.2478/s13382-013-0161-8 
Seth, A. (2016). Study of mental health and burnout in relation to teacher effectiveness among secondary school teachers. Indian Journal of Health \& Wellbeing, 7(7), 769-773.

Sharma, R. (2012). Mental health concerns of students and teachers in higher education in India. Journal of Psychosocial Research, 7(2), 203-210.

Stake, R. E. (1995). The art of case study research. Sage.

Stake, R. E. (2005). The Sage handbook of qualitative research (3rd ed.). Sage.

Uzman, E., \& Telef, B. B. (2015). Prospective teachers' mental health and their help-seeking behaviours. Dusunen Adam: Journal of Psychiatry \& Neurological Sciences, 28(3), 242-254. https://doi.org/10.5350/DAJPN2015280307

Walter, H. J., Gouze, K., \& Lim, K. G. (2006). Teachers' beliefs about mental health needs in inner city elementary schools. Journal of the American Academy of Child \& Adolescent Psychiatry, 45(1), 6168. https://doi.org/10.1097/01.chi.0000187243.17824.6c

Wang, H., Hall, N. C., \& Rahimi, S. (2015). Self-efficacy and casual attributions in teachers: Effects on burnout, job satisfaction, illness, and quitting intentions. Teaching and Teacher Education, 47(2), 120-130. https://doi.org/10.1016/j.tate.2014.12.005

Woudstra, M. H., van Rensburg, E. J., Visser, M., \& Jordaan, J. (2018). Learner-to-teacher bullying as a potential factor influencing teachers' mental health. South African Journal of Education, 38(1), 1-10. https://doi.org/10.15700/saje.v38n1a1358

Yazan, B. (2015). Three approaches to case study methods in education. The Qualitative Report, 2O(2), 134-152.

Yin, R. K. (2014). Case study research: Design and methods (5th ed.). Sage Publishing

Zhang, Y., \& Wildemuth, B. M. (2017). Unstructured interviews. In B. M. Wildemuth (Ed.), Applications of social research methods to questions in information and library science (2nd ed.; pp. 237-247). Libraries Unlimited.

Živković, P. (2018). Concurrent validity of the student teacher professional identity scale. International Journal of Cognitive Research in Science, Engineering \& Education, 6(1), 13-16. https://doi.org/10.5937/ijcrsee1801013Z

\section{[Appendix follows]}


Kratt \& Houdyshell, 2020

\section{Appendix}

\section{Interview Questions}

1. What led you to agree to participate in a research study about mental health conditions and student teaching?

2. What leads you to believe that you have a mental health condition? (diagnosis, length of time, severity, symptoms, etc.)

3. What treatment options, if any, have you utilized or explored?

4. How does having this mental health condition impact your daily life in general? As a student? As a student teacher? Are there differences between classroom experiences versus field experiences?

5. What kind of supports or interventions, if any, have you already utilized or received from the university as a student? From the College of Education (COE) as a student?

6. Tell us about any experiences you have had as a COE student while serving in a district school as it relates to your mental health condition.

7. What kinds of situations helped lessen the challenges you faced with a mental health condition while serving in a school?

8. What kinds of situations increased the challenges you faced with a mental health condition while serving in a school?

9. What suggestions do you have for the COE to improve the student teaching experience for students who have a mental health condition?

10. Is there anything additional that you believe would be helpful for us to know about your experience as a student teacher in the $\mathrm{COE}$ with a mental condition health condition?

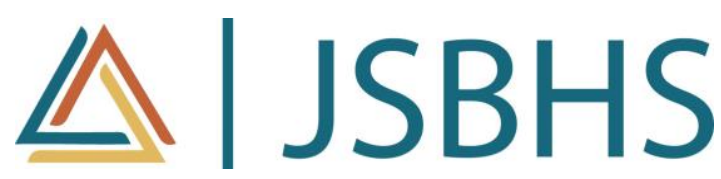

The Journal of Social, Behavioral, and Health Sciences (JSBHS), co-sponsored by the College of Health Sciences and the College of Social and Behavioral Sciences at Walden University, is a peer-reviewed, online, interdisciplinary journal focusing on theoretically-based research that addresses contemporary national and international issues. JSBHS articles include peer-reviewed research reports, brief resports, comprehensive literature reviews, books reviews, and student research. 